\title{
Coronary Computed Tomography Angiography for Assesment of Stable Coronary Artery Disease - a Cost-effectiveness Perspective
}

\author{
Roxana Hodas ${ }^{1,2}$, Ștefania Alexandra Polexa ${ }^{3}$, Manuca Rareș³, Theodora Benedek1,2 \\ ${ }^{1}$ Center of Advanced Research in Multimodality Cardiac Imaging, Cardio Med Medical Center, Târgu Mureș, Romania \\ 2 „George Emil Palade” University of Medicine, Pharmacy, Sciences and Technology Târgu Mureș, Romania \\ ${ }^{3}$ Clinic of Cardiology, County Clinical Emergency Hospital, Târgu Mureș, Romania
}

\section{CORRESPONDENCE}

\section{Roxana Hodas}

Str. Gheorghe Marinescu nr. 38

540139 Târgu Mureș, Romania

Tel: +40 265215551

E-mail: roxana.hodas@yahoo.ro

\section{ARTICLE HISTORY}

Received: January 11, 2021

Accepted: February 20, 2021

Published online February 18, 2021
Ștefania Alexandra Polexa • Str. Gheorghe Marinescu nr. 50, 540136 Târgu Mureș, Romania. Tel: +40 372653 100, E-mail: poleax stefania@gmail.com Manuca Rares • Str. Gheorghe Marinescu nr. 50, 540136 Târgu Mureș, Romania. Tel: +40 372653100 E-mail: raresmanuca@gmail.com

Theodora Benedek • Str. 22 Decembrie 1989 nr. 76 540124 Târgu Mureș, Romania. Tel: +40 265217333 E-mail: theodora.benedek@gmail.com

\begin{abstract}
Patients with chest pain presenting to the emergency room are currently investigated using either invasive coronary angiography (ICA) or noninvasive coronary computed tomography angiography (CCTA). ICA remains an expensive diagnostic tool and exposes patients to a high risk of periprocedural complication. Besides the currently available expansive economic evidence, there is still an important lingering issue: to establish, from the healthcare provider's point of view, which is the most cost-effective investigation tool for the detection of significant coronary artery disease. The aim of this article is to present the latest developments in the field of imaging tools for the detection of coronary atherosclerosis in patients with chest pain, from the perspective of a cost-effectiveness analysis.
\end{abstract}

Keywords: cost-effectiveness analysis, coronary CT angiography, stable coronary artery disease, stable chest pain, imaging

\section{BACKGROUND}

Stable chest pain is still a frequent clinical presentation to medical clinics and emergency departments worldwide. ${ }^{1}$ This leads to an increased number of invasive or noninvasive investigations with the primary aim to identify or dismiss the existence of flow-limiting coronary artery disease (CAD). ${ }^{2-4}$ This results in a continuous resource-consuming problem for healthcare providers worldwide, given the fact that CAD continues to represent the most frequent cause of health-related deaths in the European Union (EU) 5 and contributes to a consistent decrease in the quality of life.6,7 In the setting of such extensive charges, the accuracy of CAD diagnosis remains of great importance for the management of these patients. ${ }^{1}$ Despite efforts to reduce cardiovascular mor- 
tality in acute coronary syndrome (ACS) via advances in the management and implementation of up-to-date effective treatments, stable CAD continues to present high mortality rates. In the current clinical practice, invasive coronary angiography (ICA) has an essential role in the management of CAD subjects, being the current gold-standard for confirming the existence, location, and severity of CAD. ${ }^{8}$ However, ICA remains an expensive diagnostic tool and exposes patients to a high risk of periprocedural complications. ${ }^{9-11}$

Driven by its ability to provide similar information regarding the coronary tree as conventional coronary angiography, coronary computed tomography angiography (CCTA) presented a widespread diffusion in the imaging field, ${ }^{12-20}$ a fact supported by a substantial weight of clinical evidence. ${ }^{21-24}$ In these terms, CCTA permits the visualization of coronary artery lumen and wall structure at a high image quality, at a low radiation dose, ${ }^{25}$ but in a noninvasive fashion, with almost $100 \%$ accuracy in excluding significant CAD. Being typically performed in outpatient care, it is to be expected to prove less expensive as the conservative ICA, whose status as the gold standard investigation for CAD derives from its $100 \%$ diagnostic accuracy.

Currently, healthcare providers allocate significant efforts to provide the most appropriate management for stable CAD, one that is effective from both clinical and cost-effectiveness point of view. ${ }^{26}$ As a large segment of the population increases in age and develops CAD, the treatment of ischemic heart disease should be sustainable for healthcare providers. This is the basis of the current agenda of cost-effectiveness analysis (CEA). CCTA seems to be the most suitable economic tool, given the differences expected both in terms of costs and outcomes for the common aim: to detect coronary stenosis. CEA investigates different diagnostic tests in order to equally examine costs and outcomes of diagnostic guidelines, with the main aim to optimize health outcomes considering existing resources. ${ }^{27}$ Thus, CEA has the potential of promoting changes in heathcare systems based on quality-guided research. ${ }^{28,29}$ Another key beneift of CEA is represented by the fact that cost savings are defined in the presence of equivalent outcomes; thus, cost fluctuation does not actually result in a decrease of quality received by the patients. ${ }^{30}$

Besides the currently available expansive economic evidence, there is still an important lingering issue: to establish, from the healthcare provider's point of view, the costefficiency of CCTA compared with the current guideline standard or other imaging techniques for the detection of significant coronary artery disease. ${ }^{31}$

\section{RISK STRATIFICATION, A CORNER MILESTONE}

For patients presenting new symptoms of stable chest pain, it is of vital significance to implement a diagnostic workup in order to investigate the presence of CAD. ${ }^{32}$ The current standard to diagnose functionally significant CAD is ICA. However, since this procedure is costly, invasive, and associated with a high risk for further major adverse events, ICA is recommended as initial test only for subjects with a high probability of $\mathrm{CAD}$, as research has shown that obstructive CAD was identified in only $38-41 \%$ of these patients, a fact also clearly highlighted by registry data. ${ }^{33-38}$ These facts are the basis for the necessity of improving screening tools for invasive strategies. ${ }^{39-41}$ From this point of view emerges the need for a better previous risk stratification, a fact underlined by previous decision analysis indicating that the optimal diagnostic strategy in this segment of patients depends primarily on the prior probability for CAD. ${ }^{42-44}$ Moreover, there is a need to implement the concept of gatekeepers for ICA, among which CCTA has gained an increasing popularity in recent research trials.

In patients with a low associated probability of CAD, a series of studies and trials (FAME 2, COURAGE, DIAD, FACTOR 46) showed the reduction of cardiac events as very unlikely, regardless of the test used, appropriate risk factor modification, and optimal medical therapy, ${ }^{45-48}$ with no available randomized clinical trials to date to support an initial invasive strategy in order to reduce major cardiovascular end-points. ${ }^{49-51}$

A large body of evidence sustains the superiority of CCTA in low-to-intermediate risk patients, demonstrating that CCTA, either as the first or as a layering test, may represent a cost-effective initial strategy for patients with CAD prevalence of $10-50 \%$ for both near-term and longterm diagnostic periods. ${ }^{52,53}$ The decision model tree of Dewey et al. proved CCTA as the most cost-effective approach to be implemented for the $10-50 \%$ pretest likelihood of CAD, while CCTA and ICA proved to be equally effective at a $60 \%$ likelihood. ICA proved to be the most cost-effective diagnostic tool only for a pretest likelihood greater than $70 \% .52$ The decision analytic model of Halpern et al. showed a cost reduction with CCTA depending on the prevalence of $\mathrm{CAD}$, with overall costs reduced as long as the prevalence is under $85 \% .{ }^{53}$ However, in low-tointermediate prior probability of significant $\mathrm{CAD}$, the optimal diagnostic imaging test remains unclear, as a series of variables, such as costs, diagnostic test characteristics, prior calculated probability, local willingness-to-pay threshold, optimization criteria, availability, patient preference, or local team expertise, must be taken into consideration. ${ }^{32}$ 
Regarding patients with very high probability of CAD presenting stable chest pain, there is a large body of clinical trials suggesting diagnostic strategies involving ICA as the most cost-effective initial strategy for the diagnosis of stable chest pain, with a concomitant lack of clinical and health economic data in a large body of clinical trials (PROMISE, SCOT-HEART, EVINCI) to support the implementation of CCTA in subjects at high risk of CAD in real-world settings. ${ }^{31,53-55}$ However, the same studies have shown that clinical estimates of prior probability are in fact grossly overinflated in real-world implementation. Therefore, in terms of real life, this group of subjects for whom direct ICA proved to be cost-effective compared to CCTA may not actually exist. Thus, these results should only be seen as a stimulus for further required research rather than furnishing definitive conclusions.

\section{UP-TO-DATE RESEARCH}

If CCTA is to be considered a gatekeeper for ICA, correct CEAs are of great importance in the field of evidence-based science. Up to date, more than 10 large randomized clinical trials (including ACCURACY, Meijboom, CORE 64, EVINCI, PICTURE, Dewey, and the CONFIRM Registry) have compared CCTA with invasive angiography. ${ }^{56-66}$

The Coronary CT Angiography Evaluation for Clinical Outcomes: An International Multicenter (CONFIRM) registry performed a direct comparison between CCTA and ICA. The results revealed that the use of CCTA, as a gatekeeper to ICA, resulted in lower rates of follow-up catheterization for subjects presenting no or mild CAD. ${ }^{67}$

In a study conducted by Budoff et al., a $63.4 \%$ cost-saving was obtained when comparing ICA-confirmed CAD diagnosis costs with CCTA. In a similar manner, Halpern et al. obtained an overall reduction of costs when performing CCTA before ICA, at a prevalence of CAD below $85 \%$. This trend persisted for the cases of CAD with a $50 \%$ prevalence as well. ${ }^{68}$

Another series of studies compared the cost-effectiveness of CCTA prior to ICA with direct ICA. Five studies were cost-utility analyses reporting beneficial measures in terms of gained QUALYs, two of them scoring relatively high using the Drummond checklist. ${ }^{69-73}$ The most important parameter driving the cost-effectiveness of CCTA is the probability test of CAD. In low-to-intermediate probability of CAD, CCTA proved to be more effective and less costly compared to the direct invasive approach. Conversely, in patients with higher probability of $\mathrm{CAD}$, the direct invasive approach proved to be more effective and also associated with higher incremental cost-effectiveness ratios that were above the thresholds typically considered good value for money. 69,73

EVASCAN is one of the first large cost-effectiveness trials that included the largest population used for studying diagnostic accuracy in subjects with stable or suspected CAD to date. The trial included 705 patients from 40 centers and provided robust results, concluding what would become the cornerstone of further studies and guidelines. ${ }^{31}$ The main conclusion of the trial stated that in patients with intermediate risk, CCTA is the best option to rule out $\mathrm{CAD}$, especially in subjects who, for different reasons, cannot undergo ICA or present uncertain results from other diagnostic procedures. ${ }^{74-76}$ The trial also assessed the benefits of CCTA triage for intermediate-risk as a cost-saving strategy compared with the conservative "ICA for all" approach. The trade-off for these potential monetary savings is the slight reduction in accuracy and a small increase in radiation dose. ${ }^{74}$

\section{CURRENT GUIDELINE RECOMMENDATIONS}

With regard to the current recommendations of the guidelines of the European Society of Cardiology (ESC), the American College of Cardiology (ACC), and the American Heart Association (AHA) in the setting of chronic coronary syndromes (CCS), the latest ESC guideline from 2019 recommends the use of CCTA in the diagnostic and risk stratification of obstructive CAD amongst patients with stable chest pain on the basis of the pretest CAD probability, local team expertise and availability, and anticipated quality of the examination (I to IIa, B to C). ${ }^{77}$ Less prioritized by the outdated 2012 ACC/AHA guideline, the use of $\mathrm{CT}$ angiography for CCS diagnosis is disadvantaged to the detriment of functional imaging tests as the choice to be made. ${ }^{78}$ Current guidelines regarding the use of CCTA in patients with stable chest pain are predominantly derived from the results of the initial diagnostic accuracy studies. ${ }^{78}$ In this setting, the main application of CCTA consists in acting as a gatekeeper for ICA and further revascularization, with further reduction in diagnostic work-up costs. On the other hand, in its 2016 guideline, the National Health Service (NHS) of the United Kingdom controversially recommended CCTA as the first-line investigation for all patients with angina and no prior CAD..$^{79}$ Also, previous pretest probability of obstructive CAD was no longer advised. The NHS recommendation is based on a surveillance review which included each imaging modality, on the basis of which a cost-effectiveness analysis was undertaken. CCTA emerged as having a very high diagnostic sensitivity as well as a lower cost in comparison with other 
imagistic investigations, particularly ICA. ${ }^{79}$ Therefore, the analysis concluded that as a first-line investigation, CCTA offered a lower cost per correct diagnosis than any of the alternative strategies in all three risk groups of patients.

\section{FURTHER QUESTIONS}

As the most developed European countries lined up in implementing guidelines and country-specific organization recommendations, given the large grade of heterogeneity in the availability of CT scanners in other countries, the applicability of current recommendations in various healthcare systems may differ and remains to be explored. The implementation of these general indications for the assessment of stable CAD was estimated to be associated with a near $700 \%$ increase in the number of performed CCTA. ${ }^{80}$ However, the utilization of CCTA remains suboptimal related to the evidence proving its clinical efficiency, compared with other imaging techniques. ${ }^{81}$ Thus, the potential implementation of these latest recommendations for the diagnostic management of stable CAD may involve a substantial investment in CCTA infrastructure and training. Besides the field of research or large clinical trials, the use of CCTA in routine clinical practice will inevitably generate a series of equivocal CCTA scans. Consequently, attending physicians may require further imaging tests in the diagnostic work-up in order to solve the doubt generated by the equivocal results, increasing the economic burden. ${ }^{25}$

64-sclice CCTA has also been proven accurate for CAD diagnosis in most patients. ${ }^{82-85}$ However, specific groups of patients may have low-quality images as a result of a difficult scanning process. ${ }^{86}$ These groups of patients include those with tachycardic rhythm $>65 \mathrm{bpm}$, arrhythmias, obesity, coronary calcium score (CCS) $>400$, previous percutaneous coronary interventions with stent implantation, intolerance to beta-blockers, or previous coronary artery bypass graft. Up-to-date ICA may be indicated in these difficult-to-image subjects. However, newer generation CCTA instruments may provide an alternative for these cases. According to a study conducted by Burgers et al., the use of new-generation dual-source CCTA in case of difficult-toimage patients with CAD is equal in terms of effectiveness with ICA but at a cost-saving for both suspected and known CAD patients. ${ }^{85}$ Therefore, this alternative is recommended to be implemented for the assessment of patients who prove to be difficult to assess using earlier CT scanners.

There are still great expectations from future research in order to more definitively apply cost data to healthcare policy decision-making.

\section{CONCLUSIONS}

Given the current competitive economic environment, it is of great importance to understand expenditures correctly, as the increased costs of healthcare further lay the grounds for a necessary understanding of good value in healthcare.

Available economic analyses suggest the fact that with a high negative predictive value and a high diagnostic accuracy, CCTA seems to be an excellent cost-effective approach as a rule-out-test for CAD, prior to ICA, when applied to the appropriate population. However, further multicenter randomized trials are needed in order to determine the degree by which CCTA may improve clinical outcomes in patients with chest pain.

Finally, the implementation of CCTA for the evaluation of new-onset chest pain in the real world essentially depends on newly implemented health strategies, grounded on the reconfiguration of currently available assets and staffing levels.

Therefore, it becomes clear that CCTA is a definitely cost-effective imaging tool for the diagnosis of chest pain, confirming its key role in identifying the best clinical pathways that should be adopted to guarantee the optimal clinical outcome of CAD patients.

\section{CONFLICT OF INTEREST}

Nothing to declare.

\section{ACKNOWLEDGEMENT}

This research was supported via the research grant no. 103544/2016, contract number 26/01.09.2016, entitled "Increasing the research capacity in the field of vulnerable plaque imaging, based on advanced nanoparticles, fusion imaging and computational simulation - PlaqueImage", financed by the Romanian Ministry of European Funds, the Romanian Government and the European Union.

\section{REFERENCES}

1. Nasis A, Meredith I, Cameron D, Seneviratne S. Coronary computed tomography angiography for the assessment of chest pain: current status and future directions. Int J Cardiovasc Imaging. 2015;31Suppl 2:125-143.

2. J Ladapo JA, Blecker S, Douglas PS. Physician decision making and trends in the use of cardiac stress testing in the United States: an analysis of repeated cross-sectional data. Ann Intern Med. 2014;161:482-490.

3. Montalescot G, Sechtem U, Achenbach S. ESC guidelines on the management of stable coronary artery disease: the TaskForce on the management of stable coronary artery disease of the European Society of Cardiology. Eur Heart J. 2013;34:2949-3003.

4. Pundziute G, Schuijf JD, Jukema JW, et al. Head-to-head comparison of coronary plaque evaluation between multislice computed tomography and intravascular ultrasound radiofrequency data analysis. JACC Cardiovasc Interv. 2008;1:176-182. 
5. Turchetti G, Kroes MA, Lorenzoni $V$, et al. The cost-effectiveness of diagnostic cardiac imaging for stable coronary artery disease. Expert Rev Pharmacoecon Outcomes Res. 2015;15:625-633.

6. Carrabba N, Migliorini A, Pradella S, et al. Old and New NICE Guidelines for the Evaluation of New OnsetStable Chest Pain: A Real World Perspective. Hindawi BioMed Research International. Volume 2018, Article ID 3762305, 7 pages. https://doi.org/10.1155/2018/3762305.

7. Mensah GA, Roth GA, Fuster V. The Global Burden of Cardiovascular Diseases and Risk Factors: 2020 and Beyond. J Am Coll Cardiol. 2019;74:2529-2532.

8. Patel MR, Peterson ED, Dai D, et al. Low diagnostic yield of elective coronary angiography. N Engl J Med. 2010;362:886e95.

9. Patel MR, Peterson ED, Dai D, et al. Low diagnostic yield of elective coronary angiography. N Engl J Med. 2010;362:886-895.

10. Noto TJ Jr, Johnson LW, Krone R, et al. Cardiac catheterization 1990: a report of the registry of the Society for Cardiac Angiography and Interventions (SCA\&I). Catheter Cardiovasc Diagn. 1991;24:75-83.

11. Scanlon PJ, Faxon DP, Audet AM, et al. ACC/AHA guidelines for coronary angiography. Areport of the American College of Cardiology/American Heart Association Task Force on practice guidelines (Committee on Coronary Angiography). Developed in collaboration with the Society for Cardiac Angiography and Interventions. J Am Coll Cardiol. 1999;33:17561824.

12. Budoff MJ, Dowe D, Jollis JG, et al. Diagnostic performance of 64-multidetector row coronary computed tomographic angiography for evaluation of coronary artery stenosis in individuals without known coronary artery disease: results from the prospective multicenter ACCURACY (assessment by coronary computed tomographic angiography of individuals undergoing invasive coronary angiography) trial. J Am Coll Cardiol. 2008;52:1724e32.

13. Fine JJ, Hopkins CB, Ruff N, et al. Comparison of accuracy of 64-slice cardiovascular computed tomography with coronary angiography in patients with suspected coronary artery disease. Am J Cardiol. 2006:97:173e4.

14. Leber AW, Knez A, von Ziegler F, et al. Quantification of obstructive and nonobstructive coronary lesions by 64-slice computed tomography: a comparative study with quantitative coronary angiography and intravascular ultrasound. J Am Coll Cardiol. 2005;46:147e54.

15. Leschka S, Alkadhi H, Plass A, et al. Accuracy of MSCT coronary angiography with 64-slice technology: first experience. Eur Heart $\mathrm{J}$. 2005;26:1482e7.

16. Mollet NR, Cademartiri F, van Mieghem CA, et al. High-resolution spiral computed tomography coronary angiography in patients referred for diagnostic conventional coronary angiography. Circulation. 2005;112:2318e23.

17. Miller JM, Rochitte CE, Dewey M, et al. Diagnostic performance of coronary angiography by 64-row CT. N Engl J Med. 2008;359:2324e36.

18. Meijboom WB, van Mieghem CA, Mollet NR, et al. 64-slice computed tomography coronary angiography in patients with high, intermediate, or low pretest probability of significant coronary artery disease. J Am Coll Cardiol. 2007;50:1469e75.

19. Ollendorf DA, Kuba M, Pearson SD. The diagnostic performance of multislice coronary computed tomographic angiography: a systematic review. J Gen Intern Med. 2011;26:307e16.

20. Duszak Jr R, Optican RJ, Brin KP, et al. Cardiac CT and coronary CTA: early medicare claims analysis of national and regional utilization and coverage. J Am Coll Radiol. 2011;8:549e55.

21. Douglas Ps, hoffmann U, Patel Mr, et al. Outcomes of anatomical versus functional testing for coronary artery disease. N Engl J Med. 2015;372:12911300.

22. SCOT-HEART investigators. CT coronary angiography in patients with suspected angina due to coronary heart disease (SCOT-HEART): an openlabel, parallel-group, multicentre trial. Lancet. 2015:385:2383-2391.

23. Williams MC, Hunter A, Shah ASV, et al. Use of coronary computed tomographic angiography to guide Management of Patients With coronary Disease. J Am Coll Cardiol. 2016;67:1759-1768.

24. Maurovich-Horvat P, Ferencik M, Voros S, et al. Comprehensive plaque assessment by coronary CT angiography. Nat Rev Cardiol. 2014;11:390402.

25. Harden S. BSCl / RCR / RCP Standards of practice of computed tomography coronary angiography (CTCA) in adult patients: British Society of Cardiovascular Imaging/British Society of Cardiac CT. Available at: http://www.bsci.org.uk

26. Centonze M, Steidler S, Casagranda G, et al. Cardiac-CT and cardiac-MR cost-effectiveness: a literature review. Radio/ Med. 2020;125:1200-1207.
27. Mushlin Al, Ghomrawi HM. Comparative effectiveness research:a cornerstone of healthcare reform? Trans Am Clin Climatol Assoc. 2010;121:141-154.

28. Mushlin Al, Ghomrawi H. Health care reform and the need forcomparativeeffectiveness research. N Engl J Med. 2010;362:e6.

29. Shaw LJ. Cost-effectiveness and future implications for cardiovascular imaging. Can J Cardiol. 2013;29:350-357.

30. Nasis A, Meredith I, Cameron J, Seneviratne S. Coronary computed tomography angiography for the assessmentof chest pain: current status and future directions. Int J Cardiovasc Imaging. 2015;31:125-143.

31. van Waardhuizen CN, Khanji MY, et al. Comparative cost-effectiveness of non-invasive imaging tests in patients presenting with chronic stable chest pain with suspected coronary artery disease: a systematic review. Eur Heart J Qual Care Clin Outcomes. 2016;2:245-260.

32. Fihn SD, Gardin JM, Abrams J, et al. American College of Cardiology Foundation; American Heart Association Task Force on Practice Guidelines; American College of Physicians; American Association for Thoracic Surgery; Preventive Cardiovascular Nurses Association; Society for Cardiovascular Angiography and Interventions; Society of Thoracic Surgeons. 2012 ACCF/AHA/ACP/AATS/PCNA/SCAI/STS guideline for the diagnosis and management of patients with stable ischemic heart disease. J Am Coll Cardiol. 2012;60:e44-e164.

33. Napp AE, Haase R, Laule M, et al. Computed tomography versus invasive coronary angiography: design and methods of the pragmatic randomised multicentre DISCHARGE trial. Eur Radiol. 2017;27:2957-2968.

34. Skelly AC, Hashimoto R, Buckley DI, et al. Noninvasive Testing for Coronary Artery Disease [Internet]. Rockville (MD): Agency for Healthcare Research and Quality (US); 2016 Mar. (Comparative Effectiveness Reviews, No. 171.) Executive Summary. Available from: https://www.ncbi.nlm.nih.gov/ books/NBK361155/

35. Greenwood JP, Ripley DP, Berry C, et al. Effect of Care Guided by Cardiovascular Magnetic Resonance, Myocardial Perfusion Scintigraphy, or NICE Guidelines on Subsequent Unnecessary Angiography Rates: The CE-MARC 2 Randomized Clinical Trial. JAMA. 2016;316:1051-1060.

36. Williams MC, Hunter A, Shah ASV, et al.Use of Coronary Computed Tomographic Angiography to Guide Management of Patients With Coronary Disease. J Am Coll Cardiol. 2016;67:1759-1768.

37. Patel MR, Peterson ED, Dai D, et al. Low diagnostic yield of elective coronary angiography. N Engl J Med. 2010;362:886-895.

38. Go AS, Mozaffarian D, Roger VL, et al. Heart disease and stroke statistics-2013 update: a report from the American Heart Association. Circulation. 2013;127:e6-e245.

39. Bradley SM, Spertus JA, Kennedy KF, et al. Patient selection for diagnostic coronary angiography and hospital-level percutaneous coronary intervention appropriateness: insights from the National Cardiovascular Data Registry. JAMA Intern Med. 2014;174:1630-1639.

40. Bradley SM, Maddox TM, Stanislawski MA, et al. Normal coronary rates for elective angiography in the Veterans Affairs Healthcare System: insights from the VA CART program (vet-erans affairs clinical assessment reporting and tracking). J Am Coll Cardiol. 2014;63:417-426.

41. Genders TSS, Meijboom WB, Meijs MFL, et al. CT coronary angiography in patients suspected of having coronary artery disease: decision making from various perspectives in the face of uncertainty. Radiology. 2009;253:734-744.

42. Ladapo JA, Jaffer FA, Hoffmann U, et al. Clinical outcomes and costeffectiveness of coronary computed tomography angiography in the evaluation of patients with chest pain. J Am Coll Cardiol. 2009;54:24092422.

43. Min JK, Gilmore A, Budoff MJ, Berman DS, O'Day K. Cost-effectiveness of coronary CT angiography versus myocardial perfusion SPECT for evaluation of patients with chest pain and no known coronary artery disease. Radiology. 2010;254:801-808.

44. De Bruyne B, Pijls NH, Kalesan B, et al. Fractional flow reserve-guided $\mathrm{PCl}$ versus medical therapy in stable coronary disease. N Engl J Med. 2012;367:991-1001.

45. Boden WE, O'Rourke RA, Teo KK, et al. Optimal medical therapy with or without PCl for stable coronary disease. N Engl J Med. 2007;356:15031516.

46. Young LH, Wackers FJ, Chyun DA, et al. Cardiac outcomes after screening for asymptomatic coronary artery disease in patients with type 2 diabetes: the DIAD study: a randomized controlled trial. J Am Med Assoc. 2009;301:1547-1555.

47. Muhlestein JB, Lappe DL, Lima JA, et al. Effect of screening for coronary artery disease using $\mathrm{CT}$ angiography on mortality and cardiac events in 
high-risk patients with diabetes: the FACTOR-64 randomized clinical trial. JAMA. 2014;312:2234-2243.

48. Boden WE, O'Rourke RA, Teo KK, et al. Optimal medical therapy with or without PCl for stable coronary disease. N Engl J Med. 2007;356:15031516.

49. Frye RL, August P, Brooks MM, et al. A randomized trial of therapies for type 2 diabetes and coronary artery disease. N Engl J Med. 2009; 360:2503-2515

50. De Bruyne B, Pijls NH, Kalesan B, et al. Fractional flow reserve-guided PCl versus medical therapy in stable coronary disease. N Engl J Med. 2012; 367:991-1001.

51. Dewey M, Hamm B. Cost effectiveness of coronary angiography and calcium scoring using CT and stress MRI for diagnosis of coronary artery disease. Eur Radiol. 2007;17:1301e9.

52. Halpern EJ, Savage MP, Fischman DL, et al. Cost-effectiveness of coronary CT angiography in evaluation of patients without symptoms who have positive stress test results. AJR Am J Roentgenol. 2010;194:1257e62

53. Douglas PS, Hoffmann U, Patel MR, et al. Outcomes of anatomical versus functional testing for coronary artery disease. N Engl J Med. 2015;372:1291300.

54. SCOT-HEART investigators. CT coronary angiography in patients with suspected angina due to coronary heart disease (SCOT-HEART): an openlabel, parallel-group, multicentre trial. Lancet. 2015;385:2383-2391.

55. Budoff MJ, Dowe D, Jollis JG, et al. Diagnostic performance of 64-multidetector row coronary computed tomographic angiography for evaluation of coronary artery stenosis in individuals without known coronary artery disease: results from the prospective multicenter ACCURACY (Assessment by Coronary Computed Tomographic Angiography of Individuals Undergoing Invasive Coronary Angiography) trial. J Am Coll Cardiol. 2008;52:1724e1732.

56. Meijboom WB, Meijs MF, Schuijf JD, et al. Diagnostic accuracy of 64-slice computed tomography coronary angiography: a prospective, multicenter, multivendor study. J Am Coll Cardiol. 2008;52:2135e2144.

57. Miller JM, Rochitte CE, Dewey M, et al. Diagnostic performance of coronary angiography by 64-row CT. N Engl J Med. 2008;359:2324e2336.

58. Neglia D, Rovai D, Caselli C, et al. Detection of significant coronary artery disease by noninvasive anatomical and functional imaging. Circ Cardiovasc Imaging. 2015;8: e002179.

59. Budoff MJ, Li D, Kazerooni EA, Thomas GS, Mieres JH, Shaw LJ. Diagnostic accuracy of noninvasive 64-row computed tomographic coronary angiography (CCTA) compared with myocardial perfusion imaging (MPI): the PICTURE study, a prospective multicenter trial. Acad Radiol. 2017;24:22e29.

60. Dewey M, Rief M, Martus P, et al. Evaluation of computed tomography in patients with atypical angina or chest pain clinically referred for invasive coronary angiography: randomised controlled trial. BMJ. 2016;355.i5441.

61. Min JK, Dunning A, Lin FY, et al. Age- and sex-related differences in all-cause mortality risk based on coronary computed tomography angiography findings results from the International Multicenter CONFIRM (Coronary CT Angiography Evaluation for Clinical Outcomes: an International Multicenter Registry) of 23,854 patients without known coronary artery disease. J Am Coll Cardiol. 2011;58:849e860.

62. Villines TC, Hulten EA, Shaw LJ, et al. Prevalence and severity of coronary artery disease and adverse events among symptomatic patients with coronary artery calcification scores of zero undergoing coronary computed tomography angiography: results from the CONFIRM (Coronary CT Angiography Evaluation for Clinical Outcomes: an International Multicenter) registry. J Am Coll Cardiol. 2011;58:2533e2540.

63. Small GR, Yam Y, Chen L, et al. Prognostic assessment of coronary artery bypass patients with 64-slice computed tomography angiography: anatomical information is incremental to clinical risk prediction. J Am Coll Cardiol. 2011;58(23):2389e2395.

64. Shaw LJ, Hausleiter J, Achenbach S, et al. Coronary computed tomographic angiography as a gatekeeper to invasive diagnostic and surgical procedures: results from the multicenter CONFIRM (Coronary CT Angiography Evaluation for Clinical Outcomes: an International Multicenter) registry. J Am Coll Cardiol. 2012;60:2103e2114.

65. Hadamitzky M, Achenbach S, Al-Mallah M, et al. Optimized prognostic score for coronary computed tomographic angiography: results from the CONFIRM registry (COronary CT Angiography EvaluatioN for Clinical Outcomes: an InteRnational Multicenter Registry). J Am Coll Cardiol. 2013;62:468e476.

66. Shaw LJ, Hausleiter J, Achenbach S, et al; CONFIRM Registry Investigators. Coronary computed tomographic angiography as a gatekeeper to invasive diagnostic and surgical procedures: results from the multicenter
CONFIRM (Coronary CT Angiography Evaluation for Clinical Outcomes: an International Multicenter) registry. J Am Coll Cardiol. 2012;60:2103-2114.

67. Shaw LJ, Min JK, Budoff M, et al. Induced cardiovascular procedural costs and resource consumption patterns after coronary artery calcium screening: results from the EISNER (Early Identification of Subclinical Atherosclerosis by Noninvasive Imaging Research) study. J Am Coll Cardiol. 2009;54:1258-12.

68. Amemiya S, Takao H. Computed tomographic coronary angiography for diagnosing stable coronary artery disease: a cost-utility and costeffectiveness analysis. Circ J. 2009;73:1263-1270.

69. Genders TS, Meijboom WB, Meijs MF, et al. CT coronary angiography in patients suspected of having coronary artery disease: decision making from various perspectives in the face of uncertainty. Radiology. 2009;253:734-744.

70. Kreisz FP, Merlin T, Moss J, et al. The pre-test risk stratified costeffectiveness of 64-slice computed tomography coronary angiography in the detection of significant obstructive coronary artery disease in patients otherwise referred to invasive coronary angiography. Heart Lung Circ. 2009;18:200-207.

71. Min JK, Gilmore A, Budoff MJ, et al. Cost-effectiveness of coronary CT angiography versus myocardial perfusion SPECT for evaluation of patients with chest pain and no known coronary artery disease. Radiology. 2010;254:801-808.

72. Westwood M, Al M, Burgers L, et al. A systematic review and economic evaluation of new-generation computed tomography scanners for imaging in coronary artery disease and congenital heart disease: Somatom Definition Flash, Aquilion ONE, Brilliance iCT and Discovery CT750 HD. Health Technol Assess. 2013:17:1-243.

73. Litt HI, Gatsonis C, Snyder B,et al. CT angiography for safe discharge of patients with possible acute coronary syndromes. N Engl J Med. 2012;366:1393-403.

74. Hoffmann U, Truong QA, Schoenfeld DA, et al. Coronary CT angiography versus standard evaluation in acute chest pain. N Engl J Med. 2012;367:299-308.

75. Goldstein JA, Chinnaiyan KM, Abidov A, et al. The CT-STAT (Coronary Computed Tomographic Angiography for Systematic Triage of Acute Chest Pain Patients to Treatment) trial. J Am Coll Cardiol. 2011;58:14141422.

76. 2019 ESC guidelines for the diagnosis and management of chronic coronary syndromes The Task Force for the diagnosis and management of chronic. Available at: https:// doi.org/10.1093/eurhearti/ehz425

77. Finn SD, Gardin JM, Abrams J, et al. 2012 ACCF/AHA/ACP/AATS/PCNA/ SCAI/ STS guideline for the diagnosis and management of patients with stable ischemic heart disease: executive summary. J Am Coll Cardiol Immed Past Chair. 2012;60:44-164.

78. Kelion AD, Nicol ED. The rationale for the primacy of coronary CT angiography in the National Institute for Health and Care Excellence (NICE) guideline (CG95) for the investigation of chest pain of recent onset. J Cardiovasc Comput Tomogr. 2018;12:516-522.

79. OECD Health Statistics 2014 - Frequently Requested. Available at. https:// www.oecd.org/els/health-statistics-2014-frequentlyre- quested-data.htm

80. Slim AM, Jerome S, Blankstein R, et al. Healthcare Policy Statement on the Utility of Coronary Computed Tomography for Evaluation of Cardiovascular Conditions and Preventive Healthcare: From the Health Policy Working Group of the Society of Cardiovascular Computed Tomography. J Cardiovasc Comput Tomogr. 2017;11:404-414.

81. Mowatt G, Cummins E, Waugh N, Walker S, Cook J, Jia X, Hillis GS, Fraser C. Systematic review of the clinical effectiveness and cost-effectiveness of 64-slice or higher computed tomography angiography as an alternative to invasive coronary angiography in the investigation of coronary artery disease. Health Technol Assess. 2008;12:iii-iv.

82. Schuetz GM, Zacharopoulou NM, Schlattmann P, Dewey M. Meta-analysis: noninvasive coronary angiography using computed tomography versus magnetic resonance imaging. Ann Intern Med. 2010;152:167-177.

83. Khan R, Rawal S, Eisenberg MJ. Transitioning from 16-slice to 64-slice multidetector computed tomography for the assessment of coronary artery disease: are we really making progress? Can J Cardiol. 2009;25:533-42.

84. Raff GL, Gallagher MJ, O'Neill WW, Goldstein JA. Diagnostic accuracy of noninvasive coronary angiography using 64-slice spiral computed tomography. J Am Coll Cardiol. 2005;46:552-557.

85. Burgers LT, Redekop WK, Al MJ, et al. Cost-effectiveness analysis of new generation coronary CT scanners for difficult-to-image patients. Eur J Health Econ. 2017;18:731-742. 